\title{
Deborah Goldgaber* \\ Return to the Repressive: Re-thinking Nature- Culture in Contemporary Feminist Theory
}

https://doi.org/10.1515/opphil-2018-0018

Received June 14, 2018; accepted July 31, 2018

\begin{abstract}
In "History of Sexuality" (Vol I.) Foucault argued that repression is the wrong model of power, understanding it in exclusively negative terms, as external to the body it constrains and inhibits. Power may also be positive, productive, and constitutive of the body and its possibilities. Thus, an adequate account of the relation between cultural forces and the body, Foucault argues, must challenge the "repressive hypothesis" (RH). Contemporary feminist accounts of the body are structured by this same oppositional view of power Foucault assumed: to call on Rosi Braidotti’s distinction, discursive (cultural) forces are either negative or repressive (potestas) or positive and empowering (potentia). In this paper I argue that this opposition forecloses several possibilities for thinking the morphogenetic role of culture. In particular, it assumes wrongly that repressive relations cannot be productive.
\end{abstract}

Keywords: Repressive Hypothesis, Foucault, Barad, Braidotti, Haslanger, Discursive Construction, Power, Wittig, Iris Marion Young, New Materialism, Embodiment, Gender

It is not a matter of denying sexual misery, nor is it however one of explaining it negatively by a repression. The entire problem is to grasp the positive mechanism which, producing sexuality in this or that fashion, results in misery. ${ }^{1}$

\section{The discursive hypotheses}

Distinctively, feminist accounts of the body have emphasized culture's morphogenetic force. Feminist theorists describe gendered bodies as "discursively constructed": gender representations and ascription produce the very corporeal marks or features they reference. As Sally Haslanger specifies the view:

To say that an entity is "discursively constructed" is not to say that language or discourse brings a material object into existence de novo. Rather something in existence comes to have-partly as a result of having been categorized in a certain way-a set of features that qualify it as a member of a certain kind or sort. ${ }^{2}$

Here "discursive construction" names the morphogenetic power of culture to produce-through naming, sorting and representing-the very traits that these activities seem to presuppose. Thus, it is by sorting bodies by gender that we get gendered bodies. The effects of such processes feedback and strengthen the initial categories. If the "discursive hypothesis" $(\mathrm{DH})$ is right, then cultural processes that seemed descriptive and, therefore, ontologically inert are actually prescriptive-or, rather, coercive-and morphogenetic. Coercive, rather than merely normative or prescriptive, because discursive processes work through dissimulation, passing off their normative and productive force as nature.

Culture's naturalizing trick is aided by the fact that discursive construction involves a relative de-materialization of power-operating on the body without bonds and fetters or other visible physical

1 Foucault, "Power and Sex", 113.

2 Haslanger, “Sex/Gender”, 163.

*Corresponding author: Deborah Goldgaber, Louisiana State University, United States of America; E-mail:dgoldgaber@lsu.edu 
mechanisms. For example, in her seminal essay on gendered embodiment, Throwing like a Girl [1980], Iris Marion Young describes the self-inhibitions that lead to the characteristic underdevelopment of girls' bodies. Women are not the weaker sex; becoming-woman weakens the body through introverted constraints. Similarly, Monique Wittig, specifies DH in terms of a relentlessly negative relation between cultural forces and women's bodies:

[I]n the case of women, ideology goes far since our bodies as well as our minds are the product of this manipulation. We have been compelled in our bodies and in our minds to correspond, feature by feature, with the idea of nature that has been established for us. Distorted to such an extent that our deformed body is what they call "natural," what is supposed to exist as such before oppression. ${ }^{3}$

For Wittig, cultural forces (“idealogy”) repress the body's natural urges, potentials and desires, deforming the body. Such deformation is not only deemed natural, but is also positively re-signified as feminine.

On Young's and Wittig's descriptions, DH seems to imply a version of what Foucault called the "Repressive Hypothesis," a view of power as primarily inhibiting and negative. ${ }^{4}$ Interestingly, this parallel between descriptions of power as repressive and descriptions of power as discursive is rarely made explicit. ${ }^{5}$ This is likely due, at least in part, to the fact that $\mathrm{DH}$ is apparently a theory about the (morphogenetic) productivity of cultural forces. Even if Wittig insists that this productivity is an ontological illusion, the language of construction and the notion of "en-gendering" somewhat obscure the view of discourse as a negative morphogenetic force. It is also due to the fact that not all accounts of the DH imply RH. Some feminists define DH in just the sort of positive and constitutive terms that Foucault seemed to favor, though they rarely motivate these accounts with a critique of repressive versions of discursivity. Therefore, making the parallelism between some versions of DH and RH explicit will help us to see clearly what is often obscured in feminist debates on embodiment: there are at least two version of DH that split according to the opposition that Foucault sets up in his account of power in History of Sexuality (Vol 1).

"Negative" or "repressive" versions of DH are not the only, or even the most influential found in feminist accounts of the body. Many theorists argue for a positive (and politically optimistic) account of culture's morphological productivity. Rosi Braidotti, for example, sees cultural morphogenesis as a source of corporeal possibilities. Social codes, she argues, produce "enfleshed" bodies through the "intensive redefinition" of the body's forces. Following Foucault critique, Braidotti aims to think of cultural power in its creative or "constitutive" capacity. Factoring culture's constitutive force produces distinctive forms of life irreducible to any biological essence. ${ }^{6}$ Reflecting on the distinctive conceptions of cultural power that Foucault's critique opposes, Rosi Braidotti distinguishes a negative or repressive conception of power (potestas) from the positive or empowering (potentia), ${ }^{7}$ associating the latter with her own materialist approach to the body and its becoming. ${ }^{8}$

3 Wittig, "One is not born", 123

4 Foucault, History of Sexuality, Part II, 15-51.

5 For example, Iris Marion Young, revisiting the original essay "20 years later" argues that her conception of culture was overly negative, foreclosing the possibility of speaking of discursive construction as also producing capacities. Here Young's revision still entails the oppositional view of power, she identifies the negative hypothesis as entailing what today we call "able-ism." The Negative hypothesis sees gender as handi-capping of deforming what is (counter-factually) otherwise able and full-capacitated. See Young, On Female Body Experience.

6 Braidotti, Metamorphoses, 221.

7 Braidotti seems to arrive at these terms via her reading of Spinoza. Braidotti specification does not map onto Spinoza's usage. 8 For example, in a recent article, Braidotti describes her project as "exposing the repressive structures of dominant subjectformations (potestas), but also the affirmative and transformative visions of the subject as nomadic process (potentia). Here Braidotti contrasts the positive, reconstructive nomadism she has developed with the critical, diagnostic work involved in identifying potestas. See Braidotti, “A Theroetical Framework”, 4. 
Contemporary continental philosophy, Braidotti argues, has been most productive where it has thought of cultural forces in material/embodied terms. As she writes:

The notion of the embodied or enfleshed subject is central to ... the kind of philosophical materialism I support. Historically I see it as one of the most fruitful aspects of Continental philosophy.... The embodiedness of the subject is a form of bodily materiality not of the natural biological kind. I take the body as the complex interplay of highly constructed social and symbolic forces: it is not an essence, let alone a biological subject, but a play of forces, a surface of intensities, pure simulacra without original. This intensive redefinition of the body situates it within a complex interplay of social and affective forces. ${ }^{9}$

Social and symbolic forces act upon, engage, and elicit the body's intentional and affective dimensions. The body's "intensive redefinition," the "entanglement" of the physical, social, symbolic and affective forces are positive sources of corporeal possibility. Braidotti does not deny that power (also) "entraps" the body; she argues that limiting power to entrapment leads to an inadequate account of power, which must be supplemented by an account of discursivity as potentia.

With the preceding analysis, my aim was not to motivate a reassessment of repressive versions of DH in light of Foucaultian critiques of power. Rather, it was to show that feminist accounts of discursive construction split on Foucaultian lines, according to the opposition he proposes in his re-framing of power in History of Sexuality. Yet these accounts share an assumption (with Foucault) they ought to question instead: namely, that cultural forces are either disabling or enabling, creative or destructive. This assumption, I argue, ignores the possibility that repressive (cultural) forces may incur or incite a (productive) biological response. It also fails to factor the possibility that new corporeal possibilities may entail the destruction of other biological possibility. Indeed, as we will see, the opposition structuring accounts of discursive construction is only plausible if we assume no interaction between biological and cultural forces, no plasticity or responsiveness, no re-organization of the body's resistance in response to the various ways it may be solicited and constrained by culture. As soon as we think of a "positive" or productive response to repressive power-imagine the case, for example, of neural plasticity-the oppositional view of power collapses. We must, in other words, return to the repressive hypothesis (and its critique) in order to develop more adequate accounts of culture's morphogenetic force.

\section{Nature/culture; potestas/potentia}

The main difference between the two versions of $\mathrm{DH}$ is the way each figures the relation between nature and culture. In neither case is discursivity constitutive or productive of the biological body. In other words, the oppositional account of discursivity relies on the nature/culture opposition. On the repressive version of DH, the body's gendered features lack ontological reality. Discursive effects marking the destruction of biologically-given capacities are deformations positively resignified. For these accounts, the body is essentially biological, its capacities and possibilities the effects of biological forces. Culture acts only as a negative, supplementary force, without which the body would go back to being what it would have been. The body does not lack a biological or organic essence; indeed, discursivity is just the repression of its expression.

By contrast, DH as potentia (viz. Braidotti) sees cultural forces as constitutive of corporeal capacities. Culture, it is argued, cannot be understood in purely repressive or negative terms-to think otherwise would be to embrace a kind of biological determinism limiting the possibility and scope of its historical transformation. For Braidotti, "culture" and "power" name, among other things, the positive conditions of possibility for subjective transformation. Adopting and experimenting with bodily practices and habits, we create new corporeal possibilities. Just as "performing" gendered scripts produces a gendered body "as its stabilized effect", it follows that altering these scripts, subverting or making these scripts visible

9 Braidotti, Metamorphosis, 20; emphasis mine. 
produces new subjective possibilities. ${ }^{10}$ Foucault suggests as much, writing that corporeal experimentation (including but not limited to drugs, sexual activity) is as much a critical-epistemological, as ontological activity; we discover our limits of possibility in the course of attempts to form ourselves differently and otherwise. ${ }^{11}$

Less clear for positive accounts of cultural morphogenesis is how to establish the scope or extent of this cultural productivity or how to factor the limits of what Foucault referred to as the "technologies of the self." If culture is productive, what relation does this productivity have to the biological body? Karen Barad has emphasized this problem in her critical reading of both Foucault and Judith Butler's version of DH. "If discursive practices constitute a productive social or cultural field, how much of the very matter of bodies both human and nonhuman, can be accounted for?" she asks. ${ }^{12}$ For Barad, accounts of discursive construction fail as explanations of the body because they cannot, in principle, specify the limits of culture's productivity. In particular, they cannot specify their relation to extra-discursive forces. Having constitutively excluded biology ${ }^{13}$ from the field of cultural production or power, they cannot account for the limits of or resistance to culture's morphogenetic power. ${ }^{14}$ For Barad, thinking DH consistently requires thinking cultural forces as entangled with biological forces.

Barad does not distinguish between "negative" and "positive" versions of DH, which makes it harder to evaluate her critique. Barad's question is inapt for negative versions of DH, where "biology" clearly names both the possibility and limit of discursive effects. But it perspicaciously identifies a problem for the sort of "continental materialism" Braidotti endorses. While the latter allows us to think of the matter of bodies as saturated with power-even as the site for the contest of morphogenetic forces-we do not have any clear sense of how or if this "intensively redefined" corporeal materiality relates to any natural, presumably biological, materiality. Even if the proposed form of materialism aims to deconstruct a notion of a biological body that would be opposed to or distinct from cultural forces, the problem with positive versions of DH (potentia) is that only cultural forces are active or productive. As we saw with Braidotti, if "the body [is] the complex interplay of highly constructed social and symbolic forces" the biological and organic forces simply go missing.

Barad asks if such accounts "do not require us to understand matter as a purely cultural phenomenon, [as] the end result of human activity".

And if so, is this not yet another reenactment of the crossing out of nature by culture? And if not, then how can we explain what nature is in relation to this cultural field? Are there significant ways in which matter matters to the process of materialization ${ }^{15}$

Discursivity's ontological incontinence comes from thinking cultural forces as productive without a corresponding, rigorous reflection on the nature of the relations between biological and cultural forces. Such accounts, she argues, will have the effect of "crossing out" or cancelling the productivity of organic matter or "Nature" because, in the absence of such critical reflection, they end up reinscribing traditional metaphysical dualisms, thinking the relation of culture/nature in terms of (productive) form/ (passive)

10 Butler, Gender Trouble, 180.

11 "Criticism indeed consists of analyzing and reflecting upon limits. But if the Kantian question was that of knowing what limits knowledge has to renounce transgressing, it seems to me that the critical question today has to be turned back into a positive one: in what is given to us as universal, necessary, obligatory, what place is occupied by whatever is singular, contingent, and the product of arbitrary constraints? The point, in brief, is to transform the critique conducted in the form of necessary limitation into a practical critique that takes the form of a possible transgression. This entails an obvious consequence: that criticism is no longer going to be practiced in the search for formal structures with universal value, but rather as a historical investigation into the events that have led us to constitute ourselves and to recognize ourselves as subjects of what we are doing, thinking, saying.” Foucault, “What is Enlightenment”, 32-50

12 Barad, Meeting the Universe, 64.

13 This is a constitutive exclusion because in order to define the discursive field as the field of cultural activity, biological activity has first to be bracketed and then, necessarily, defined as extra-discursive.

14 Barad, Meeting the Universe, 64.

15 Ibid. 
matter or temporal succession, with cultural forces supplanting, overwriting, and re-forming a nonhistorical biological body never contemporaneous with culture.

The solution, according to Barad, is to begin with the question of relation, rather than bracketing the biological or organic as such. Beginning with the question of relation will motivate novel accounts of the relations between cultural and biological forces, and generate schemas capable of thinking the radical entanglement of nature and culture. Her own speculative project-which she refers to as agential realismdevelops an account of culture-nature as intra-activity, where the latter names a relation constitutive of its relata. Intra-activity, is in a sense generalized discursivity. ${ }^{16}$

It is beyond the scope of this paper to reconstruct and evaluate Barad's account of intra-activity, but it is important to note that she motives her account by arguing that we cannot consistently think discursivity without losing sight of the biological materiality of the body. If we want to think of cultural forces as morphogenetic, we must also be willing to think intra-activity. While this is arguably true for positive (potentia) versions of $\mathrm{DH}$, it is not true for "repressive" versions of $\mathrm{DH}$ (potestas). Without taking into account the latter, Barad's revisionary project is not sufficiently motivated. Moreover, and this is perhaps most critical, if Barad's critique points out the pitfalls of thinking of culture in productive terms, her notion of intra-activity remains one-sidedly thought as and in terms of productivity. She never broaches the question of what sort of intra-activity repression might entail.

\section{The Metaphysics of potentia}

Broadly speaking, the post-structuralist theories targeted by recent New Materialist critiques such as Barad's are said to fail not because they think of culture in terms of potentia-as constitutive of the body's essential features and capacities-but because they think of culture's constitutive power at the expense of the biological. Such accounts involve an incomplete critique of biological essentialism-viz., the view that body is essentially and intrinsically biological-insofar as they fail to effectively challenge traditional ways of thinking the relation between biology and culture.

In one way or another, these accounts, operating with a positive version of $\mathrm{DH}$, foreclose talk of an extra-discursive body-a body meaningfully outside of historical or cultural forces, broadly construed. This (debunked) extra-discursive body is usually identified with the body we (falsely) refer to as "natural," "biological" or "organic." Their point is not to argue that there is nothing like a biological body, but that this biological body cannot be understood as extra-discursive. Unfortunately, there is no alternative in the offing for thinking of the biological as "internal" to discourse. Vicki Kirby, for example, has argued that "textualist" analyses of the body-here she singles out Judith Butler in particular-have given us no meaningful way of talking of the body's biological substance. The "text," Kirby writes, never seems to include the "itinerary of the virus" nor the "electrical activity that plays across the synapse". ${ }^{17}$ The biological stuff of the body recedes to the outside (of the text) even as the body is re-doubled as the effect of cultural activity.

According to Barad's critique, attempts at deconstructing the nature/culture opposition, of bringing the body "inside" have awkwardly led to two bodies-a body conceived wholly as the effect of culture and a disavowed and dislocated natural or biological body bracketed and silenced. Thus, as Kirby argues, despite Butler's promise to speak explicitly to the question of cultural morphogenesis-that is the shaping force of culture on a material body-this morphogenetic activity is specified as the production not of a material body but of the body qua its phenomenal appearance. ${ }^{18}$ Rather than answer the question of how cultural forces

16 Barad suggests that the challenge that discursivity poses to classic distinctions between first- and second-order processes, reality and representation, cannot be contained or limited to special cases like gender. This suggests both that discursivity is not limited to the sphere of culture-also characterizing biological processes-and that culture and biology are mutually constitutive. This would mean that the effects of cultural processes cannot be limited a priori to the field of culture; that culture produces biology and reciprocally that biology forms culture.

17 Kirby, Telling Flesh, 97.

18 Berressem, "matter that bodies". 
shape a material, presumably biological body-the question Butler initially poses in Bodies that Matter, her notion of "cultural morphogenesis" ends up answering an entirely different question: namely, how are perceptions of bodies that appear to have certain "natural" or "biological" features produced and how are such beliefs sustained ${ }^{19}$

Similarly, on Foucault's articulation, the genealogical conception of the body would foreclose all talk of an extra-discursive "biological” body "outside" or prior to cultural morphogenesis, revealing instead the body's plastic, historical essence:

Genealogy, as an analysis of origins, is thus situated within the articulation of the body and history. Its task is to expose a body totally imprinted by history and the process of history's destruction of the body.$^{20}$

According to its genealogical conceptualization, the body is always already articulated with history. That is, there is not first a (stable) body, which has its intrinsic biological properties, that then gets entangled in a set of "historical" relations. For Foucault, the body's articulation with history is constitutive of the properties that non-genealogical accounts (naively) take to be intrinsic. Only a constitutively historical body could be a body "totally imprinted by history." But if "articulation" gestures towards thinking the relation of bodily materiality and historical forces in terms of what Barad calls intra-action, a relation constitutive of its relata and of their difference, the notion of "imprint" re-installs genealogical accounts of the body in a classical metaphysical frame. The relation between history and the body is like the relation between a passive surface and an imprinting process.

Barad, in her critique of Foucault (more of which below), does not challenge his view that the body it constitutively historical-which she reads as the claim that the biological body and the cultural body are "intra-actively" articulated-but rather Foucault's way of thinking articulation in terms of cultural "imprinting". ${ }^{21}$ According to Barad, the relation of articulation-the metaphysical relation it entails-needs to be radially rethought. Doing so will result in novel schemas for thinking the material entanglements that produce the body's morphology. ${ }^{22}$ Yet, the problem facing Foucault's account of the body is surely not just inscriptivism.

Why, for instance, should we be compelled to think that all the body's features are constitutively historical rather than just some-assuming that here "history" designates non-biological forces? Why does Foucault insist on the radical claim that the body has no intrinsic properties-where 'intrinsic' refers to those features the body would have whatever the cultural conditions it faced-rather than the more modest revisionary claim that some of the properties we thought were intrinsic to the body are actually the effects of cultural activity? ${ }^{23}$ Secondly, as genealogists, how should we conceive the nature of a constitutive relation that would preserve the difference between "body" and "history"? As Derrida has put the point, does Foucault not "ruin" the notion of history precisely at the moment that he aims to generalize it-by crossing out the terms with which it contrasts, namely nature/biology? Do we not get, with Foucault's proposal, a historical materiality that thoroughly dislocates the biological, organic body? Finally, for Foucault, does the body totally imprinted by history not totally elide the question of the "history" proper to biology, namely evolution?

To begin to answer these questions, and to see what motivates the genealogical approach, we return to the view of history/culture/power it opposes. As we have seen, Foucault opposes the genealogical approach to what he refers to in History of Sexuality as the "repressive hypothesis." On the repressive model, the image of cultural power is that of a counter-force pushing inward upon that, which in its absence, would

19 Butler, Bodies the Matter, 16.

20 Foucault, "Nietzsche, Genealogy, History", 148; emphasis mine.

21 For the seminal "materialist" critique of Foucault's inscriptivism see Butler, "Foucault and the Paradox of Bodily Inscriptions," 601-607. Butler argues that Foucault's account both rejects and entails an extra-discursive body and thus remains incoherent.

22 In particular, such schemas would be helpful in thinking the metaphysics of epigenesis.

23 Indeed, as we saw above, feminist theorists have most often argued that it is only those features of the body associated with gender that are not "intrinsic" in the relevant sense. 
freely express itself. Such a model, Foucault argues, misses entirely the sense in which power is constitutive of that which it is said to suppress. Crucially, Foucault's point in challenging the repressive hypothesis is not to insist that cultural power does not work repressively-dampening, discouraging or muting the body's vital forces-but rather by inciting and invigorating these forces with the allure of the taboo. His point is that power constitutes or produces what it regulates. Emphasizing this point aims to correct a tempting but ultimately misleading interpretation of Foucault's critique of RH: namely that his critique of the repressive model is a critique of the view that power constrains/dampens rather than activates/amplifies the body's intrinsic vitalities. "Repressive" power is no less repressive, in the relevant sense, when it incites, amplifies or compels the body's intrinsic vital forces. $\mathrm{RH}$ is operative whenever the absence of repression leaves us with something like the body's free, natural or authentic expression.

Foucault is clear: the repressive hypothesis he opposes entails the counterfactual claim that what power affects would, in its absence, return to being what it was, to expressing itself according to its essential or natural manner. ${ }^{24}$ The aim of Foucault's critique of the repressive hypothesis is to motivate the view that power is constitutive of that which it regulates (the body) and hence cannot in principle be thought as acting from the outside or as analytically distinct from the body's essential forces. For Foucault, sexuality-an index of the body's vitality-cannot be analytically distinguished from the vital powers investing it; the body's regulation cannot (ex hypothesis) be distinguished from its constitution.

Anticipating the problems of thinking of cultural forces as constitutive, Foucault writes:

[T] he purpose of the present study is in fact to show how deployments of power are directly connected to the body-to bodies, functions, physiological processes, sensations, and pleasures; far from the body having to be effaced, what is needed is to make it visible through an analysis in which the biological and the historical are not consecutive to one another ... but are bound together in an increasingly complex fashion in accordance with the development of the modern technologies of power that take life as their objective. Hence I [envisage]...a 'history of bodies' and the manner in which what is most material and most vital in them has been invested..$^{25}$

Here, it seems, Foucault insists on a realist, materialist interpretation of the body that would specify how (cultural) power invests-directly connects with-what is "most vital" in the body. Such an account should make the body doubly vital: the investment of an already vital materiality with yet more vitality. ${ }^{26}$ Why, then, against his own explicit precautions, does Foucault persist in thinking materiality as matter culturally/ historically vitalized?

Though Foucault recognizes the need for an analytic of the body that factors both its biological and cultural provenance, and though he argues that the constitutive effects of power must be thought in terms of the interplay of biology and history, he fails, as Barad underlines, to provide a schema for the body's materiality capable of factoring, "the complex fashion" in which "the biological and the historical...are bound together." Genealogy thus leaves us with an account in which the biological and the historical-or the relation between nature and culture-are, after all, thought consecutively. Those who have followed Foucault-including Braidotti-seem to follow the same pattern of elisions.

If "biology" (qua the body's initial material conditions) is displaced by its articulation with culture, why is this displacement always figured as erasure, rather than in terms that allow us to speak of preservation? Why should the historical, technical or cultural supplementation of nature not imply both preservation and modification? If, as a deconstructive logic would suggest, culture is the essential supplement of

24 This corrects a tempting, but ultimately misleading interpretation of Foucault: namely that his critique of the repressive model is only critique of the view that power constrains the body's intrinsic vitalities. "Repressive" power is no less repressive when it incites, amplifies or compels the body's vital forces-so long as we see that the opposite of repression as something like the body's free natural or authentic expression.

25 Foucault, The History of Sexuality, 151-2; my emphasis.

26 Interestingly, Foucault describes culture's constitutive work, now as destructive- "history's destruction of the body" or equivalently, the historical destruction of the body's history-and now as productive-in terms of power's "investments." However, whether thought in terms of productivity or destruction, the becoming-historical of the body seems to entail the disappearance of nature. The articulation of the body with history is not the articulation of historical and biological forces, in which the latter are thought in terms of their complex interplay, it is of a play of power with itself, or with its past effects. 
nature, why does conceptualizing this supplementation lead to the erasure of the very difference that it seeks to explain? As it stands, on Foucault's genealogical schema, the body's materiality seems to become essentially historical/cultural by becoming post-biological. As Karen Barad correctly notes, the index of history's power is the erasure of the biological body.

Thinking the constitutive power of culture never seems to yield a re-vitalized biological body. The body that is produced by these investments of power is never a biological body. ${ }^{27}$ According to the deconstructive and genealogical logics, it seems that the latter resist thinking the body as organic or biological to the degree that they resist thinking the body in terms of origins or initial conditions.

Interestingly, in Foucault's earlier work, when focusing on the way disciplining regimes shape the body, disciplinary power's discursive effects were often figured repressively, as the destruction or inhibition of the body's (innate or intrinsic) capacities. In contrast to the elaborate torture rituals breaking the body of the regicide in the unforgettable opening salvo of Discipline and Punish-a body whose "prior" organization, we must recall, tenaciously resisted its own disintegration-the meticulous timetables and regimens of the prison and the workhouse seemed to re-write or overwrite the bodily rhythms of the prisoner/ laborer. "Discipline" appeared to name a certain kind of destruction-albeit a vital destruction-of a prior organization or health. If such destructions are vital, we might speculate, it is insofar as they produce another form of life on the grounds of a prior form.

These accounts seemed to already challenge the RH layed out in History of Sexuality, albeit in different terms than the ones Foucault articulates in that text. Cultural forces do not merely inhibit organic life; they produce or impose different patterns or forms of life. This thought would justify Foucault's insistence that power must be thought in constitutive (rather than negative/inhibiting) terms. This thought is also in tension-if not incompatible-with the idea that there is something like an extra -discursive body which would set for itself an internal form or norm. Notions of disciplinary power suggests a possibility that Foucault's later work suspends: that cultural forces could be both constitutive and repressive. What power regulates might be constitutive not because productive of the body's capacities (donating or implanting new rhythms that supplant the body's original rhythms) but because the organic body dynamically responds to its own "intensive" regulation by re-organizing, re-structuring or re-defining itself. If we put pressure on the assumption that constitutive force is positive/productive rather than negative/repressive we will have more resources for thinking the body in its difference from history/culture.

\section{The potential of potestes: or the repressive hypothesis revisited}

In the previous section we focused on problems with accounts of discursivity as potentia. I want now to demonstrate the ways that some rather classic feminist accounts of gendered embodiment invite us to reconsider the tendency in deconstructive and genealogical accounts to reject the explanatory power of repression or the negative force of culture. From De Beauvoir to Iris Marion Young, gender's "discursive construction" has always referred us to forces that inhibit, deform, or disable; Culture names a negative, sculpting force, repressing the body's natural capacities, hindering its vitality and preventing its flourishing.

As we saw above, on Wittig's account, the features constitutive of gendered bodies are not constitutive of biological capacities or properties-quite to the contrary the idea of "nature" to which woman's bodies are compelled to correspond is a deformation of nature, a deformation taken to be natural. The deformations that "make" women mark them as inferior. In this context, the familiar assertion that the male body goes unmarked takes on a double sense. The male body serves as the corporeal norm in contrast to which woman

27 In the earlier Discipline and Punish, Foucault tends to describe disciplinary mechanisms and regulatory regimes associated with prisons, schools, and hospitals in negative terms, of how the latter deform bodies. In the biolpolitical frame, however, he substitutes the model of constraint and deformation for the model of the articulation of body-power that would be constitutive rather than repressive. The disciplining model, even when confidently asserting that a soldier is not born but made, seems to assume the body entrapped by disciplinary power as a set of (pre)existing conditions, possibilities or virtualities to be differentially actualized by power. The power that would be constitutive of these (pre-existing) conditions or possibilities-that would produce these conditions as the effect of its application-is not yet specified. 
can appear as difference or Other; and the male body can serve as a corporeal ideal because it is unmarked by the deformations characterizing feminine embodiment.

In her classic essay on gendered embodiment, Iris Marion Young considers the various ways that cultural forces may compel in the absence of visible material constraints and hobbling devices. As Young writes, "typically, the feminine body under-uses its real capacity, both as the potentiality of its physical size and strength, and as the real skills and coordination that are available to it". ${ }^{28}$ Despite the apparent existence and function of certain corporeal and kinesthetic capacities, these capacities are shut-off, inhibited or otherwise unavailable. Importantly, on Young's account cultural forces are in no way constitutive of the body's capacities; indeed, her argument depends upon the body having "real capacities" that are neglected and wasted through their inhibition.

If, in the case of women, "gender" names the set of cultural conditions that act as off- switches or inhibitors for the development of expression of organic possibilities, in the absence of gender (or other social or cultural) "disablers," it follows that women's physical comportment and capacities would be considerably closer to men's. On Young's account, what makes a corporeal difference gendered is that a biological capacity is suppressed in support of a hierarchical social scheme. Gender disables girls. Girls are culturally disabled while biologically able. Thought from the point of view of its essential possibilities, the body remains biological. "Gender" marks the conditions constraining the biological body, and the forces that lead it to have a characteristic shape as a result of these constraints.

DH as negative cultural morphogenesis imagines cultural forces, I want to suggest, as analogous to the pruning techniques that create bonsai trees. Without such pruning techniques, we might say, the tree would have developed according to its natural capacities. Similarly, without the constraining effects of "gender"the ensemble of cultural forces differentially constraining bodies-the body would have developed according to its natural capacities. In both cases, pruning (and gender) would be constitutive of certain features the body comes to have-but these features are negative, ontologically speaking. Explaining these features requires explaining the lack or absence of a certain morphological feature. Such negative features do not change any facts about the body, instead, the morphological changes in question could be deduced from knowledge of these facts together with knowledge of how "outside" forces impinge on their expression.

However, why think-as Young clearly does-that biological forces are inert or indifferent, unresponsive to the kind of repressive activities of culture-and the costs they imply? If culture can be negative or destructive, why not think it can also be positive, ameliorative? Of course, it may be precisely to avoid the problems faced by constitutive accounts-a reluctance to engage in speculative metaphysical projects-that leads philosophers such as Young to figure cultural morphogenesis in exclusively negative terms. On the one hand, one of the features of such accounts is the elegance and explanatory power of their claims. Gender hierarchies are produced and maintained by practices that seem retrospectively to justify these hierarchies. Gender ought to be eliminated to eliminate these sorts of corporeal harms. On the other hand, such accounts require thinking of gender and sexual difference in exclusively negative terms-and involve certain able-ist presuppositions that present the flourishing, desirable body as a male body. Are men not gendered? Does becoming-women not lead to certain corporeal possibilities-even, and especially if such possibilities were spandrels? The latter, on balance, motivate challenging the view of cultural morphogenesis as potestes.

Perhaps, rather than thinking of gendered bodies (and bonsai trees) as dis-abled or non-actualized expressions of prior/pure biological potentials, we ought instead question the assumption that male bodies (and trees not bonsai-pruned) represent the fulfilled expression of their respective biological possibilities. If cultural/environmental forces may inhibit, may we not also assume that these forces optimize or actualize, or otherwise positively provide for the full development of biological capacities? To think otherwise would be to assume without warrant that culture, where it does not disable, is benign or inert with respect to biological capacities.

If biological possibilities had something like enabling conditions, would the right description be that culture actualizes prior biological possibility, or, rather, that "culture" names the necessary (positive) conditions for the expression of biological possibility? Which is to say that biology must be thought as

28 Young, “Throwing Like A Girl”, 148. 
anticipating and inter-acting with culture. If extra- biological forces are necessary or essential to biological possibilities, we would not be justified in thinking of cultural forces in exclusively negative terms; cultural forces, even if they are sometimes directly inhibiting or repressive, could also be destructive by withholding their (positive) constitutive powers. Though, I will not pursue this line of re-thinking the relation between nature and culture further here, I want to underline that it requires us to think of biology as "open" to culture and it is precisely this "openness" that poses the problem I have been tracking through this paper: namely that of the erasure of nature by culture. The distinctive problem facing "intra-activists" like Barad is how to think the difference or closure of biology once we have insisted that it is constitutively openness. ${ }^{29} \mathrm{I}$ want to suggest in the closing section that we may find it productive to think the extent to which the intraaction of nature and culture may be thought while maintaining the closure or "exteriority" of the biological.

We can retain the view that cultural morphogenesis is negative vis a vis certain biological capacities or possibilities and consider that negative morphogenesis may, at least in certain cases, trigger a plastic response from the biological body, such that "negative" and repressive cultural morphogenesis would now appear as the positive condition for the appearance of biological capacities or possibilities which, in the absence of inhibiting forces, would not have appeared. An example of the sort of plastic response I have in mind may be found in descriptions of the "plasticity" of the visual cortex..$^{30}$ According to this literature, inhibition or impairment of the "normal" operation of the visual cortex is a condition for sighted people to learn to read Braille. ${ }^{31}$ Repressing the cortex's "normal" function-for example, wearing suitable blindfolds for a prescribed period of time-seems to "liberate" the function of the "visual" cortex, allowing sighted-people to use the latter to spatialize and differentiate between haptic differences. If this cortical "re-purposing" were a plastic response to inhibition, it would, arguably, offer a case of the sort of economy of forces "constitutive repression" describes.

The suggestion that morphogenesis may be both constitutive (of the body's capacities) and negative (inhibiting and repressive) offers us a way of thinking of biological and cultural forces as mutually productive and reproductive while maintaining that biological processes are "closed" to cultural forces. While there are good reasons to think that negative or repressive models of cultural morphogenesis will not give us the whole story of cultural morphogenesis, at least in the context of feminist theory, where it is a matter of thinking gendered embodiment, we do have good reason to favor the repressive accounts. Emphasizing the repressive character of gender preserves the view that gendered embodiment, all things considered, has indefensibly high corporeal costs. However, the notion of constitutive repression provides for interesting intersections with disability theorists who have precisely argued against the sort of able-ist perspective that we find in Young's account of gendered embodiment. ${ }^{32}$

If Foucault was right to question the RH, he did not make explicit precisely how it should be resisted, or that there is more than one way to resist the repressive hypothesis. Either, the repressive hypothesis is wrong because 1) power does not essentially repress or 2) because repression is (at least in some cases) constitutive. Repression is constitutive I have argued, just in the case biological forces are morphogenetically responsive to the effects of cultural forces. The theme of plasticity, or morphogenetic responsiveness, demonstrates that what is negative and what positive, what productive and what destructive depends, as Foucault's teacher Canguilhem never tired of pointing out, on the perspective one takes. ${ }^{33}$ If feminists, following Foucault, have largely bracketed the question of the productive or constitutive effects of gender "orthopedics" on biological processes, it is because they have regarded biology exclusively from the perspective of cultural activity. It may be time to shift perspective and regard this cultural activity from the point of view of biology.

29 On my view this is the distinctive task of "new materialist" speculative thought. In New Materialist projects, data, models and schemas from biology (see Wilson, Gut Feminism, Haraway, Staying with the Trouble), physics (Barad, Meeting the Universe), forensics (Kirby, Quantum Anthropologies) and neuroscience (Malabou What Should We Do?; Wilson, Neural Geographies) take the place of linguistic and semiological schemas as intuitive models for how to conceive of bodies and their relations.

30 Hamilton, "Cortical plasticity associated with Braille learning”, 57.

31 Amedi, “The Occipital Cortex,” 306.

32 See for example, Wendell, The Rejected Body.

33 Canguilhem, The Normal and the Pathological. 


\section{References}

Amedi, Amir, Lotfi B. Merabet, Felix Bermpohl, and Alvaro Pascual-Leone. "The Occipital Cortex in the Blind: Lessons About Plasticity and Vision." Current Directions in Psychological Science Vol 14, Issue 6 (2016), 306 - 311.

Barad, Karen. "Posthumanist Performativity: Toward an Understanding of How Matter Comes to Matter.” In Belief, Bodies, and Being: Feminist Reflections on Embodiment, edited by Deborah Orr, 120-147. Lanham, MD: Rowman and Littlefield Publishers, 2006.

Barad, Karen. Meeting the Universe Halfway: Quantum Physics and the Entanglement of Matter and Meaning. Durham, NC: Duke University Press, 2007.

Berressem, Hanjo. “matter that bodies: gender in the age of a complex materialism.” Gender Forum 2 (2002). http://www.genderforum.uni.koeln.de/mediating/btm.html.

Braidotti, Rosi. Metamorphoses: Towards a Materialist Theory of Becoming. New York: Polity Press, 2002.

Braidotti, Rosi. "A Theoretical Framework for the Critical Posthumanities". Theory, Culture \& Society 0:0 (2018), 1-31.

Butler, Judith. "Foucault and the Paradox of Bodily Inscriptions". Journal of Philosophy 86: 11 (1989), 601-607.

Butler, Judith. Gender Trouble: Feminism and the Subversion of Identity. New York: Routledge, 2006.

Butler, Judith. Bodies That Matter: On the Discursive Limits of "Sex". New York: Routledge, 1993.

Canguilhem, Georges. The Normal and the Pathological, trans. Carolyn R. Fawcett \& Robert S. Cohen. New York: Zone Books, 1991.

De Beauvoir, Simone. The second sex. New York: Vintage Books, 1952.

Foucault, Michel. “Nietzsche, Genealogy, History.” In Nietzsche. edited by John Richardson \& Brian Leiter, 139-164 0xford: University Press, 1984.

Foucault, Michel. The History of Sexuality. Volume One: An Introduction. New York: Vintage Books, 1980.

Foucault, Michel. “What is Enlightenment?" In The Foucault Reader, edited by Paul Rabinow, (32-50). New York: Pantheon Books, 1984.

Foucault, Michel. “Politics, Philosophy, Culture: interviews and other writings 1977-1984” Edited by Lawrence D. Kritzman, 111-124. New York Routledge, 1988.

Hamilton, Roy H. and Alvaor Pascual-Leone. "Cortical plasticity associated with Braille learning." Trends in Cognitive Sciences 2:5 (1998), 168-174.

Haraway, Donna. Staying with the Trouble: Making Kin in the Chthulucene. Durham, NC: Duke University Press, 2016.

Haslanger, Sally. "The Sex/Gender Distinction and the Social Construction of Reality." In Routledge Companion to Feminist Philosophy, edited Ann Garry, Serene J. Khader, Alison Stone. New York: Routledge, 2017.

Kirby, Vicki. Telling Flesh: The Substance of the Corporeal. New York: Routledge, 1997.

Kirby, Vicki. Quantum Anthropologies: Life at Large. Durham, NC: Duke University Press, 2011.

Malabou, Catherine. What Should We Do with Our Brain?. New York, NY: Fordham University Press, 2008.

Sadato, Norihiro. “How the Blind 'See' Braille: Lessons From Functional Magnetic Resonance Imaging.” Neuroscientist 11 (2005), 577-582.

Wendell, Susan. The Rejected Body: Feminist Philosophical Reflections on the Disabled Body. London: Routledge, 1996. Wilson, Elizabeth. Gut Feminism Durham, NC: Duke University Press, 2007.

Wittig, Monique. "One is not born a woman." In The Essential Feminist Reader, edited by Estelle B. Freedman, 359-367. New York: Modern Library, 2007.

Young, Iris Marion. On Female Body Experience: “Throwing Like a Girl” and Other Essays. Oxford: University Press, 2005. 